\title{
Abdominal wall procedures: the benefits of prehabilitation
}

\author{
Nathan Knapp ${ }^{1}$, Breanna Jedrzejewski², Robert Martindale ${ }^{1}$ \\ 'Division of Gastrointestinal and General Surgery Department of Surgery, Oregon Health and Science University, Portland, OR 97239, USA. \\ 2Division of Plastic and Reconstructive Surgery, Department of Surgery, Oregon Health and Science University, Portland, OR 97239, USA.
}

Correspondence to: Dr. Nathan Knapp, Department of Surgery, Oregon Health and Science University, 3181 S.W. Sam Jackson Park Rd, Portland, OR 97239, USA. E-mail: knappn@ohsu.edu

How to cite this article: Knapp N, Jedrzejewski B, Martindale R. Abdominal wall procedures: the benefits of prehabilitation. Plast Aesthet Res 2020;7:7. http://dx.doi.org/10.20517/2347-9264.2019.69

Received: 6 Dec 2019 First Decision: 6 Feb 2020 Revised: 11 Feb 2020 Accepted: 12 Feb 2020 Published: 21 Feb 2020

Science Editor: Alexander F. Mericli Copy Editor: Jing-Wen Zhang Production Editor: Tian Zhang

\begin{abstract}
Prehabilitation for abdominal wall procedures provides an opportunity to further modify patient risk factors for surgical complications. It includes interventions that optimize nutrition, glycemic control, functional status, and utilization of the patient's microbiome pre-, intra-, and postoperatively. Through a multidisciplinary and anticipatory approach to patients' existing co-morbidities, the physiological stress of surgery may be attenuated to ultimately minimize perioperative morbidity in the elective setting. With increasing data to support the efficacy of prehabilitation in optimizing surgical outcomes and decreasing hospital length of stay, it is incumbent on the surgeon to employ these practices in elective abdominal wall reconstruction. Further research on the effects of prehabilitation interventions will help to shape and inform protocols that may be implemented beyond abdominal wall procedures in an effort to continually improve best practices in surgical care.
\end{abstract}

Keywords: Prehabilitation, perioperative optimization, abdominal wall reconstruction, minimize co-morbidities

\section{INTRODUCTION}

Achieving optimal surgical outcomes for ventral hernia repairs (VHRs) is inherently challenging. Patients who require complex reconstruction of the abdominal wall are commonly overweight, deconditioned, malnourished with or without sarcopenia, and are often chronically infected/inflamed in the setting of the previously placed synthetic mesh. Most patients in need of reconstruction have had prior repairs/

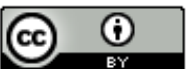

(C) The Author(s) 2020. Open Access This article is licensed under a Creative Commons Attribution 4.0 International License (https://creativecommons.org/licenses/by/4.0/), which permits unrestricted use, sharing, adaptation, distribution and reproduction in any medium or format, for any purpose, even commercially, as long as you give appropriate credit to the original author(s) and the source, provide a link to the Creative Commons license, and indicate if changes were made.

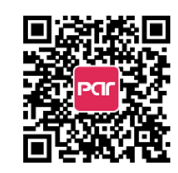




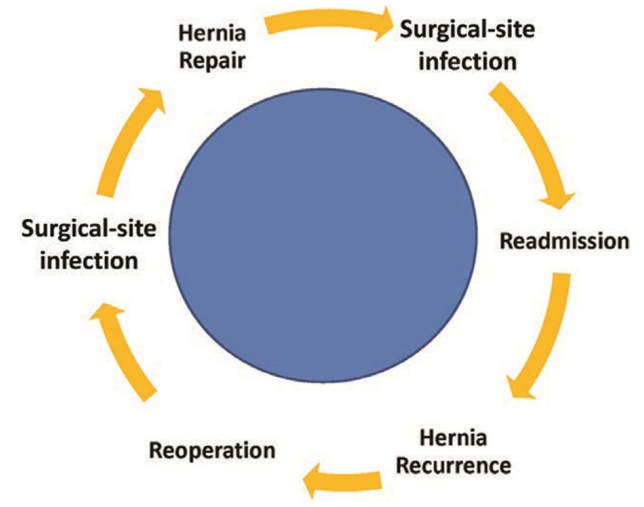

Figure 1. The vicious hernia cycle ${ }^{[10]}$

recurrences or have other significant comorbidities affecting their surgical fitness. Optimizing surgical outcomes and minimizing perioperative morbidity in this patient population requires careful preparation and planning.

\section{EPIDEMIOLOGY}

The burden of VHR and abdominal wall reconstruction (AWR) is increasing not only with regards to incidence but also in the case complexity, contributing to overall higher rates of complications ${ }^{[1,2]}$. While infection remains the most common postoperative complication, the issue of hernia recurrence is arguably the most commonly discussed and used to monitor the success of an outcome ${ }^{[3-6]}$. Following each subsequent repair, the risk of recurrence is linear to and directly related to the number of repairs ${ }^{[7]}$. The financial burden for complications status post hernia surgery are significant: patients with recurrent hernias constitute a minority (15\%) of the AWR patient population, yet account for half of the total spending for hernia surgery ${ }^{[1]}$. Recurrent hernia patients tend to be older with more significant medical comorbidities, and are associated with higher hospital and post-discharge health care costs such as readmissions, emergency department visits, etc. The magnitude of increased financial burden is likely under-reported as other expenses are more difficult to capture and quantify, including skilled nursing facilities, long-term acute care, wound care, home health services, and hospital readmissions to hospitals other than that of the primary procedure ${ }^{[8]}$. Perioperative surgical site occurrence (infection, seroma, and wound ischemia/dehiscence) increases the risk of hernia recurrence at least three-fold ${ }^{[5]}$. Surgical site infection (SSI) has been shown not only to be independently associated with an increased rate of SSI at subsequent operation in an otherwise clean wound bed, but also to act as a marker of increased case complexity $^{[9]}$. A vicious cycle often develops whereby a ventral herniorrhaphy can lead to an unfortunate pattern of bacterial infection, hernia recurrence, reoperation, and hospital readmission [Figure 1$]^{[10]}$. With an increasing emphasis placed on readmission to determine reimbursement, this cycle looms even larger on the minds of hernia surgeons ${ }^{[11]}$. Therefore, the surgeon should consider optimization of any and all factors that can promote optimal patient recovery.

\section{THE METABOLIC EFFECTS OF SURGERY}

Large hernia repairs and AWR result in considerable surgical stress that induce a predictable sequence of metabolic and physiologic changes in the patient. Further evaluation of these metabolic changes highlights areas for intervention that may allow the patient to respond to the stress with a more favorable physiologic state in the perioperative period. Immediately following surgical incision, the body initiates a response on multiple levels, including the neuroendocrine system, the sympathetic system, and the hypothalamicpituitary axis. This concert of effects leads the body to tilt toward a catabolic state to provide a metabolic substrate for mounting an acute phase response to the surgical trauma. 
Table 1. Surgeon modifiable risks for preventing complications

\begin{tabular}{lcc}
\hline Preoperative & Immediate perioperative & Postoperative \\
\hline Glycemic control & Skin prep selection & Resistance exercise/early ambulation \\
Smoking cessation & Antibiotics & Glycemic control \\
Nutrition & Glycemic control & High protein intake \\
- Metabolic prep & Hyperoxygenation & Early enteral feeding \\
- Carbohydrate loading & Drapes/wound protectors & Microbiome \\
Clearing S. Aureus & MIS surgery & - Probiotics \\
Weight loss & & - Limiting antibiotics \\
Prehabilitation & & Minimize narcotics \\
- Cardiac/pulmonary conditioning & & \\
- Resistance exercise & & \\
\hline
\end{tabular}

MIS: Minimally Invasive Surgery

Activation of the sympathetic pathway induces a hyperglycemic state via gluconeogenesis and glycogenolysis. Simultaneously, a surge in stress hormones including cortisol, glucagon, prolactin, and growth hormone mediated by the hypothalamic-pituitary axis contributes to insulin resistance and therefore an inability for the body to correct hyperglycemia. In the acute perioperative period, persistent hyperglycemia inhibits immune function and thus surgical recovery by driving catabolic changes via cortisol and glucagon, translating to breakdown of skeletal muscle, loss of lean body mass, and significant deconditioning. While a patient's preoperative physical fitness and young age may also compensate for proteolysis, fat metabolism primarily serves to minimize protein breakdown by mobilizing glycerol and fatty acids for energy usage. However, increased insulin levels and tissue insulin resistance present in times of stress yield a relative decrease in adipose breakdown. Recent literature demonstrates that immune-related nutrients such as glutamine and arginine may be depleted postoperatively and that their replacement may improve surgical outcomes ${ }^{[12]}$. While the effects on the modulation and attenuation of the inflammatory response to the catabolic effects of surgery by omega-3 fatty acids [eicospentanoic acid (EPA) and docosahexaenoic acid (DHA)] are well documented, recent data suggest that they also serve as a substrate for production of specialized pro-resolving molecules (SPMs). SPMs not only accelerate the resolution of inflammation, decrease post-surgical pain, and enhance the function of macrophages and neutrophils in bacterial killing and clearance, but they do so without increasing the inflammatory state in the process ${ }^{[13,14]}$. Thus, micronutrient supplementation with vitamins may be warranted in patients who are unable to resume a balanced enteral diet in the days following surgery.

\section{PREOPERATIVE MODIFIABLE RISK FACTORS}

The preoperative preparation and optimization serve to acknowledge and modify risk factors that may negatively impact surgical outcomes. Table 1 summarizes the factors that are reviewed in this review.

\section{Obesity}

Over $60 \%$ of AWRs are performed on obese patients ${ }^{[15]}$ and obesity increases the risk of numerous complications, including seroma, dehiscence, fistula, infections, reoperation, and thromboembolic events. Numerous studies by bariatric surgeons confirm the high incidence of incisional hernias as well as increased rates of wound infections in the obese patient population ${ }^{[16]}$. The reduction of postoperative incisional hernias and wound complications with laparoscopic gastric bypass motivated development of the technique ${ }^{[17]}$. However, the risk of hernia recurrence has been shown to positively correlate with increased body mass index (BMI) regardless of the type of repair performed ${ }^{[18-20]}$. While excess weight must be addressed with patients desiring hernia repair, it is not feasible to expect all hernia patients to achieve ideal weight prior to an operation. We have found that hernia recurrence and surgical site occurrence rates are prohibitively high in patients with a BMI $>50$. Therefore, at our institution, elective repairs for patients with BMI > 50 are not performed unless they present with acute concern for bowel compromise. 
Weight loss counseling should be a routine component of preoperative visits for those patients with BMI $>35$. This counseling involves review of specific dietary modifications, exercise regimen, dietician consult, and establishment of realistic weight loss goals. A reasonable rate of weight loss entails $0.5 \mathrm{~kg}$ or one pound per week with a 15-30-pound deficit over 3-6 months. Even with the support of a multidisciplinary clinical team, successful weight loss is greatly variable. Should the patient not meet weight loss goals with dietician support, the date of surgery may be postponed and a referral may be placed to bariatric surgery for evaluation.

In cases where the patient elects to proceed with a weight loss operation, the literature remains split regarding timing of hernia repair. A study using NSQIP data for all VHRs showed an increased risk of infection at 30 days with concurrent VHR and bariatric surgery (sleeve gastrectomy or Roux-en-Y); however, the increased risk did not exceed that expected of dual procedures ${ }^{[21]}$. Thus, the authors of the review advocated for a combined approach to minimize the morbidity of two otherwise separate procedures. We would agree that, with a relatively small ventral hernia in a patient undergoing a laparoscopic sleeve gastrectomy, the benefit of concurrent repair would outweigh separate anesthetic events. However, in our experience, patients undergoing a gastric bypass or who require AWR have improved outcomes after they experience the full scope of benefit from bariatric surgery, including, but not limited to, metabolic, endocrine, and hormonal changes, weight distribution, cardiopulmonary enhancement, and increased mobility. In general, we recommend waiting until the patient's weight has plateaued (typically 18-24 months post-bariatric surgery), and then scheduling a definitive hernia repair 3-4 months later.

\section{Smoking}

Tobacco smoking widely increases the risk of postoperative complications in most procedures, and hernia repair is without exception ${ }^{[22-25]}$. A recent study using NSQIP data examined 30-day outcomes in patients undergoing elective hernia repairs and showed that current smokers were at increased risk of reoperation, readmission, death, wound, and pulmonary complications ${ }^{[26]}$. Several studies examining the effects of smoking have found an increase in wound infection rate after hernia surgery and have identified smoking as an independent risk factor for the development of incisional hernia after abdominal surgery ${ }^{[23,27,28]}$. Smoking has a multifactorial detrimental effect on wound healing due to its reduction of oxygen tension levels in the blood and tissue, disruption of microvasculature, and alteration in surgical site collagen deposition ${ }^{[29-31]}$. VHR and AWR involve several components that may compromise wound healing and promote infection such as undermined skin flaps, myofascial advancement flaps, mesh products, reduction of chronically incarcerated hernia contents, and other concurrent gastrointestinal operations such as fistula take-downs. These factors are compounded with problems associated with active tobacco use, further motivating smoking cessation prior to surgery. Establishing the timing of the "last" cigarette is key as smoking cessation at least one month prior to an operation has been shown to reduce the risk of complications ${ }^{[25]}$. A prospective trial showed that infection rates of compliant patients quickly approach those of nonsmokers after four weeks of abstinence ${ }^{[25]}$. A systemic review and meta-analysis confirmed the benefit of smoking cessation on postoperative outcomes and showed that the magnitude of the benefit rises significantly with each week of cessation up to the four-week mark ${ }^{[32]}$. While the debate continues regarding nicotine replacement in the preoperative setting due to concern for vasoconstriction and impaired healing, several studies maintain it has no impact on surgical outcomes ${ }^{[29,33]}$.

For all patients who desire elective complex VHR at our institution, we require a minimum of 30 days smoking cessation preoperatively with allowance for nicotine replacement formulations as needed. Urine cotinine (metabolite of nicotine with a longer half-life) is checked at least 2 weeks prior to surgery to allow rescheduling in case of positive testing. Of note, the use of nicotine-replacement products can result in a positive urine cotinine test. If there is serious concern about a patient's ongoing smoking status, a urine anabasine level can be checked, which is an alkaloid only present in tobacco and not in any replacement products $^{[34]}$. 


\section{Glycemic control in perioperative period}

Glycemic control pre-, intra-, and postoperatively has been proven essential for reducing complications in elective surgery, particularly infection ${ }^{[35-37]}$. Hyperglycemia has been shown to have numerous adverse effects at the cellular level including altered chemotaxis, phagocytosis, pseudopod formation, and oxidative burst, all of which prevent neutrophils from functioning optimally ${ }^{[38]}$. In diabetic patients or those with suspected hyperglycemia, glycemic control should be measured with hemoglobin A1c (HbA1c), which gives an indication of glycemic control over the previous 2-3 months. While a goal HbA1c of $6.5 \%$ is ideal, the risk of infection rises significantly at values $>7.5 \%{ }^{[35]}$. Those patients with difficulty in achieving a HbA1c below $7.5 \%$ warrant additional education and assistance from an endocrinologist, diabetic nutritionist, and/ or diabetes nurse educator.

In the early 2000s, a large randomized controlled trial (RCT) demonstrated that tight glucose control (80$110 \mathrm{mg} / \mathrm{dL}$ ) resulted in a decrease in ICU and surgical patient mortality giving rise to the popularity of strict glucose regulation ${ }^{[39]}$. In the years after this study, the risks of hypoglycemia and its complications were found to outweigh the benefits of meticulous glucose protocol $(80-110 \mathrm{mg} / \mathrm{dL})^{[40]}$. Currently, perioperative blood sugar control in both diabetic and non-diabetic patients should aim for $120-160 \mathrm{mg} / \mathrm{dL}$ to minimize complication risks ${ }^{[40-42]}$. Postoperative hyperglycemia remains a significant risk factor for the development of surgical site occurrences; it has been reported that even one episode of serum glucose of > $200 \mathrm{mg} / \mathrm{dL}$ increases the risk of wound dehiscence ${ }^{[37,43]}$. Strict protocols for preventing hyperglycemia and glycemic interventions have effectively reduced rates of hyperglycemia and improved outcomes ${ }^{[43,44]}$.

\section{Sarcopenia}

Sarcopenia refers to a combination of muscle atrophy and replacement by fibrosis or adipose $\mathrm{e}^{[45]}$. This degenerative loss of muscle mass is most strongly associated with aging and is commonly a component of underlying pathologic processes such as cancer or liver disease. It may also occur in relatively healthy individuals if they are obese and inactive. Compared to sarcopenia in non-obese patients, sarcopenia in obesity is associated with a decrease in overall survival ${ }^{[46]}$. Sarcopenia is quantified using computed tomography by measuring a cross-sectional muscle area $\left(\mathrm{cm}^{2} / \mathrm{m}^{2}\right)$ of the paraspinous muscles at the $\mathrm{L} 3$ level and comparing the values to sex-specific cutoffs ${ }^{[45,47]}$. The presence of sarcopenia in surgical and critical care patients has been shown to be a predictor of poor outcomes such as surgical site occurrence, length of stay (LOS), and need for rehabilitation ${ }^{[48-53]}$. Increased ventilator dependence and overall mortality were seen in elderly trauma patients found to be sarcopenic ${ }^{[49]}$. Some retrospective data with VHR patients show an association of sarcopenia with increased postoperative complications and hernia recurrences ${ }^{[54]}$, whereas other preliminary reviews of prospective data fail to show a significant correlation ${ }^{[55]}$. The true role of sarcopenia in AWR and VHR requires further investigation, but methods to preserve and improve lean body mass would likely have a positive impact on patient outcomes ${ }^{[56]}$.

\section{Conditioning and prehabilitation}

It has been widely accepted that poor physical fitness is associated with poor surgical outcomes. While surgical risk calculators use biometric variables and laboratory data from the NSQIP database to estimate 30-day perioperative risks, quantifying functional status might be a better predictive tool ${ }^{[57]}$. Reddy et al. ${ }^{[58]}$ found that time to complete a stair climb in a preoperative setting was strongly associated with complication rates after abdominal surgery. The stress of this exercise likely simulates the physiologic demand induced in surgery and may help triage patients for fitness optimization. This concept, known as preconditioning or prehabilitation, serves to improve functional status leading up to an elective operation utilizing a multidisciplinary approach that includes psychological, physical, and nutritional interventions. Numerous studies have been completed over the past decade to investigate the utility of prehabilitation and demonstrate improved preoperative functional capacity ${ }^{[59]}$, rate of return to preoperative function after abdominal surgery ${ }^{[60]}$, and reduction of complication rates in elective abdominal aortic aneurysm repair ${ }^{[6]]}$. 
Given significant heterogeneity in the surgical diseases being studied and the specifics of the prehabilitation programs, there is some variability in conclusions and no large-scale evidence of one program exists to support its use ${ }^{[62]}$. Liang et al. ${ }^{[63]}$ completed the first RCT of prehabilitation in VHR patients in 2018. They showed that the prehabilitation group (which consisted of a multidisciplinary consultation with a nutritionist, physical therapist, hernia navigator, weekly group meetings, and daily goals checklists for diet and exercise) were more likely to be without hernia or other complications at one month. A recent study identified surgical prehabilitation as an independent predictor of five-year disease-free survival in patients with stage III colorectal cancer ${ }^{[64]}$.

\section{Nutrition}

The literature well-establishes that poor nutritional status translates into higher rates of postoperative complications and adverse outcomes for patients undergoing elective surgery ${ }^{[65]}$. Despite knowledge of this, the surgeon buy-in regarding preoperative nutritional optimization remains lackluster. Few major centers have organized programs to evaluate and manage preoperative nutritional status. Successfully identifying and intervening on nutritionally replete patients in the preoperative setting has potential to significantly decrease complications, length of stay, and readmissions based on multiple RCTs ${ }^{[6-68]}$.

Undernourished patients may be identified through one of several simple screening tools. Nutritional Risk Screening 2002 and Nutrition Risk in Critically Ill (NUTRIC score) are both validated systems that project risk of impairment caused by the metabolic stress of the clinical condition ${ }^{[69]}$. NUTRIC was initially calculated from six variables: age, APACHE II score, SOFA score, number of comorbidities, days from hospital to ICU admission, and IL-6. The current NUTRIC score has excluded IL-6 and remains validated $^{[70]}$. It is important to remember these scores are risk assessment scores and not nutritional indicators.

The complexity of a patient's nutritional evaluation exceeds a single laboratory value. While albumin and prealbumin have historically been used as markers of nutritional status, they lack both the sensitivity and specificity for detection of malnutrition. During an inflammatory state, the production of these visceral proteins is decreased, making the relevance of the absolute values of these proteins even more limited after the onset of illness. There are still reliable data demonstrating that low preoperative albumin levels are associated with increased postoperative complications, but it is not clear that malnutrition is definitively linked to hypoalbuminemia ${ }^{[71]}$.

Adequate energy intake (both total calories and protein) is clearly important for postoperative recovery, and enteral feeding should begin as soon as possible for nearly all surgical patients. For patients in the hospital and recovering from the stress of major surgery, data from interventions on elderly and critically ill patients show that resistance exercise combined with protein goals of $1.5-2.5 \mathrm{~g} / \mathrm{kg} /$ day optimizes preservation of muscle mass and functional status ${ }^{[72-77]}$.

A more interesting and proactive concept is the use of preoperative nutritional strategies. Preoperative immune and metabolic modulation gained traction following a series of data by Braga et al. ${ }^{[78-80]}$. and Gianotti et al. ${ }^{[81]}$ in the early 2000s. They demonstrated reduction of complications, LOC, and total cost of hospitalization with delivery of a specific "immune-enhancing" formula for five days prior to operation. This "immune-enhancing" formulation contained supplemental amounts of omega-3 fatty acids (DHA and EPA), arginine, and nucleotides. The benefit of this formula was demonstrated in both well-nourished and undernourished patients. Although the complete range of mechanisms has not been elucidated, several animal models and clinical studies propose improvement of protein kinetics, wound healing, lymphocyte function, M1 to M2 macrophage conversion (transitioning macrophages from pro-inflammatory and microbiocidal functions to more extracellular matrix building and wound healing functions), and blood flow 
via nitric oxide vasodilation with arginine supplementation ${ }^{[12,13,82-84]}$. Omega-3 fatty acids/fish oils dampen the metabolic response to stress, decrease inflammation, regulate bowel motility via vagal efferents, and stimulate the resolution of the inflammatory response by the endogenous production of SPMs ${ }^{[12,13,82,85,86]}$. Several large meta-analyses in the past decade have added support to the use of perioperative metabolic manipulation. This concept has been shown to be beneficial not in the perioperative period but also when given only preoperatively with essentially preparing the host for the metabolic insult of surgery. The overall conclusions from these studies are that immune-enhancing formulations (more so than other nutritional regimens) lead to decreased overall infections, a reduction in hospital LOS, a decrease in overall complication rate ${ }^{[87-90]}$, and one study even reporting a decrease in mortality ${ }^{[91]}$.

Another area of metabolic manipulation that has been explored is preoperative carbohydrate loading, which has shown usefulness mostly in reducing perioperative hyperglycemia/insulin resistance ${ }^{[92,93]}$. In a standard protocol, patients consume a 300-mL isotonic clear beverage with $50 \mathrm{~g}$ of complex carbohydrate three hours prior to surgery to decrease insulin resistance in the perioperative period. The original carbohydrate loading studies administered the isotonic formulations the night prior to surgery and the morning of surgery with the concept of maximally loading the myocardium, liver, and muscle with glycogen. Subsequent studies have shown that the carbohydrate loading the night before surgery is not necessary ${ }^{[94]}$. Reported outcomes with this regimen include: no increased risk of aspiration, decreased postoperative insulin resistance, maintenance of muscle strength, decreased patient anxiety, and possibly decreased LOS but no major difference in major clinical significant outcomes such as reduced infections or length of stay ${ }^{[95-97]}$. While the European Society for Clinical Nutrition and Metabolism consensus guidelines for surgical nutrition endorses carbohydrate loading ${ }^{[9,99]}$, further studies are needed to better elucidate quantity and optimal timing of intervention.

\section{Skin preparation, antibiotics, and the microbiome}

The literature suggests that acute changes in the host microbiome may alter metabolism on a systemic level. A majority of surgeons and hospitals instruct patients to shower with chlorhexidine gluconate soap the night prior to and the morning of surgery. A Cochrane Database review in 2015 summarizing seven studies and over 10,000 patients showed that, while they reported a decrease in skin bacterial colonization, there was no reduction of surgical-site infections with use of chlorhexidine compared to other agents ${ }^{[100]}$. Furthermore, a study using prospectively collected data in VHR patients actually suggested the use of prehospital chlorhexidine scrub increases the risk of infection ${ }^{[101]}$. While preoperative bathing can certainly reduce bacteria counts on the skin, it does not clearly translate into positive impacts on surgical outcomes. It may disrupt normal skin flora and therefore remove the competitive inhibition that usually prevents pathogenic bacteria from proliferating. These antibacterial soaps destroy not only pathogenic bacteria but also commensal strains ${ }^{[102]}$. However, more research is necessary before making any definitive changes to standard of care. Our program has eliminated the night before surgery chlorhexidine showers as we believe that the elimination of normal skin flora for long periods before surgery allows potential pathogens to colonize.

The data on the choice of skin preparation in the operating room are more conclusive and stem from two major trials. A prospective trial by Swenson et al. ${ }^{[103]}$ with over 3200 patients demonstrated that iodine skin preparation was superior to chlorhexidine preparations. Then, a prospective randomized trial was published reporting that chlorhexidine was superior to iodine ${ }^{[104]}$. Swenson and Sawyer ${ }^{[105]}$ then reanalyzed the data from both studies and concluded that the decreased infection rate was related to the alcohol in preparations. Duraprep and Cloraprep had similar infection risk, whereas the iodine preparation without alcohol was associated with higher surgical site infections (SSI) rates.

Staphylococcus aureus is the most common culprit in postoperative surgical infections and the rate of chronic colonization in the patient population is rising. Several studies have been conducted to investigate 
the utility of decolonization prior to a planned operation with significant beneficial results. A randomized control trial including over 6000 patients evaluated infection rates in those pretreated for 5 days with twicedaily nasal mupirocin and daily chlorhexidine showers to a placebo group ${ }^{[106]}$. The results showed a $44 \%$ decrease in postoperative $S$. aureus infections in the treated group. Several other prospective trials with the implementation of a prescreening and eradication protocol showed similar reductions in infections in patients undergoing elective orthopedic operations ${ }^{[107]}$. The logistics of screening and subsequently treating these patients need streamlining, but it is clearly cost-effective if performed according to a protocol.

According to joint guidelines developed by several professional surgical and pharmacist societies, prophylactic antibiotics (a first-generation cephalosporin) should be administered within the first hour before incision to decrease surgical-site infection in patients undergoing routine $\mathrm{VHR}^{[108]}$. Specifically, antibiotic administration should occur as close to incision as possible according to a recent large study using NSQIP data ${ }^{[109]}$. Antibiotics should be re-dosed during the operation, if necessary, taking into account the half-life of the drug, blood loss, and the use of cell saver. If planned, or inadvertent, violation of the colon occurs during the operation, additional antimicrobial coverage is warranted to cover for Gramnegative species and anaerobes (commonly second-generation cephalosporin or a carbapenem). The BMI of the patient must also be taken into consideration, as many of these VHR patients are obese and therefore require higher than standard doses of antibiotics to reach effective levels. One large survey showed that only $66 \%$ of patients with a BMI $>30$ received adequate prophylactic antibiotic doses ${ }^{[110,111]}$. Retrospective and anecdotal literature support continued postoperative antibiotics in the presence of surgical drains, but no high quality or Level 1 data validate this practice ${ }^{[112]}$. It is important to remain cognizant regarding the drawbacks of prolonged antibiotics use with respect to alteration of the gut microbiome and potential development of antibiotic-associated diarrhea and Clostridium difficile. While the exact ideal duration of antibiotics continues to be debated, prospective studies of prophylactic antibiotics support discontinuation upon skin closure ${ }^{[113-116]}$.

The gut microbiome has been shown to play a key role in the human stress response to critical illness ${ }^{[17-121]}$. When healthy and diverse, the microbiome supports symbiosis, homeostasis, and gut barrier function. The gut microbiome is affected by numerous factors that often arise in this patient population, including administration of broad-spectrum antibiotics, proton-pump inhibitors, vasopressors, and opioids, as well as decreases in luminal nutrient delivery and even changes to the exposed partial pressure of oxygen if the bowel is opened. Probiotics (live microorganisms which confer beneficial effects to the host when given in sufficient quantities) ${ }^{[122]}$ and prebiotics (food ingredients which are largely non-digestible fibers that induce the growth of beneficial microorganisms in the colon) have emerged as potential treatments to help reduce postoperative infections by supporting a healthy gut microbiome. Several randomized controlled trials using pro- and prebiotics have been conducted in various surgical patient populations ${ }^{[123]}$ in an effort to prevent specific infections, e.g., MRSA ${ }^{[124]}$. Numerous high quality meta-analyses make it clear that the use of pro- and prebiotics lowers the rates of SSIs, urinary tract infections, and sepsis ${ }^{[125-128]}$.

\section{Enhanced recovery after surgery, opioid reduction, anxiety, and miscellaneous}

Enhanced Recovery After Surgery (ERAS) protocols were first developed in patients undergoing colorectal surgery, but are now used widely throughout surgical specialties. ERAS protocol has resulted in shorter hospitalizations, reduced complication rates, lower readmissions, and lower healthcare costs ${ }^{[129-131]}$. Having a protocolized and multidisciplinary approach to the care of complex patients, such as AWR patients, in the pre-, intra-, and postoperative settings is clearly the best strategy for success.

Intraoperative wound protectors in abdominal surgery are employed to protect the wound edges from bacterial contamination and to minimize mechanical trauma. Several clinical trials have been performed to investigate their role in preventing SSIs with some success ${ }^{[132-134]}$. Plastic adhesive skin barriers used to 
prevent contamination are popular with some surgeons, but current data show no real impact on the rate of SSIs in general surgery ${ }^{[135]}$. The impact of surgical drains in the presence of synthetic mesh during AWR has been largely debated; however, a retrospective study provided evidence that their use does not increase SSI and may be protective against surgical site occurrences such as seroma ${ }^{[136]}$. Supplemental oxygenation in the perioperative period has been studied in colorectal surgery with two landmark studies showing a benefit by reducing SSIs ${ }^{[137,138]}$. A meta-analysis favored supplemental oxygen protocols in higher-risk populations ${ }^{[139]}$; however, there are no studies specific to AWR.

Another difficult topic in open abdominal surgery is pain control. Multimodal pain control with both pharmacological and non-pharmacological techniques are continuously being revisited to find the optimal regimen. Pain, and therefore pain control, is very subjective and has to be approached on an individual basis. Common pharmacological modalities include systemic opioids, local or regional blocks, central neuraxial infusions, acetaminophen, non-steroidal anti-inflammatory drugs, gamma-aminobutyric acid analogs, and beta-blockers to name a few ${ }^{[140]}$. Several non-pharmacological techniques such as acupuncture, music therapy, and hypnosis have mixed evidence regarding efficacy. The role of preoperative anxiety on postoperative experience is often overlooked and may be an avenue for improvement. A meta-analysis of 54 studies showed an association between preoperative anxiety and postoperative pain and analgesia requirements $^{[141]}$. In addition to psychological preparation, proper education, and open communication of risks, benefits, and expectations prior to surgery, music therapy may be an additional strategy to help ease anxiety ${ }^{[142]}$. Music likely shifts the patient attention and aids in cognitive coping. One study showed that patients report lower pain scores when exposed to music in the post-anesthesia care unit ${ }^{[143]}$ and a metaanalysis showed music leads to reduced anxiety in mechanically ventilated patients, as evidenced by lower respiratory rates and systolic blood pressures, and may even reduce sedative and analgesia requirements ${ }^{[144]}$.

\section{CONCLUSION}

As the incidence and complexity of VHR and AWR continues to rise, so does the importance of addressing all adjustable elements to achieve optimal outcomes. Identifying and intervening on these modifiable risk factors in the pre-, intra-, and immediately postoperative period is key to consistent success. It could certainly be argued that outcomes for these increasingly complex cases are less dependent on operative technique and more dependent on prehabilitation, addressing patient comorbidities preoperatively, adequate glucose control, focus on proper nutrition, and awareness of the microbiome.

\section{DECLARATIONS}

\section{Authors' contributions}

Participated in accumulation of data, literature review, writing and editing the manuscript: Knapp N, Jedrzejewski B, Martindale R

The authors have had equal contributions to this article.

\section{Availability of data and materials}

Not applicable.

\section{Financial support and sponsorship}

None.

\section{Conflicts of interest}

Dr's Knapp and Jedrzejewski have no conflicts of interest. Dr. Martindale has no direct conflicts of interest in this manuscript or subject matter but remains a consultant for Bard and Allergan. 


\section{Ethical approval and consent to participate}

Not applicable.

\section{Consent for publication}

The authors give consent for publication and release copyright issues.

\section{Copyright}

(c) The Author(s) 2020.

\section{REFERENCES}

1. Poulose BK, Beck WC, Phillips SE, Sharp KW, Nealon WH, et al. The chosen few: disproportionate resource use in ventral hernia repair. Am Surg 2013;79:815-8.

2. Poulose BK, Shelton J, Phillips S, Moore D, Nealon W, et al. Epidemiology and cost of ventral hernia repair: making the case for hernia research. Hernia 2012;16:179-83.

3. Hawn MT, Gray SH, Snyder CW, Graham LA, Finan KR, et al. Predictors of mesh explantation after incisional hernia repair. Am J Surg 2011;202:28-33.

4. Merkow RP, Ju MH, Chung JW, Hall BL, Cohen ME, et al. Underlying reasons associated with hospital readmission following surgery in the United States. JAMA 2015;313:483-95.

5. Sanchez VM, Abi-Haidar YE, Itani KMF. Mesh infection in ventral incisional hernia repair: incidence, contributing factors, and treatment Surg Infect (Larchmt) 2011;12:205-10.

6. HöerJ, Lawong G, Klinge U, Schumpelick V. Factors influencing the development of incisional hernia. A retrospective study of 2,983 laparotomy patients over a period of 10 years. Chirurg 2002;73:474-80.

7. Flum D, Horvath k, Koepsell T. Have outcomes of incisional hernia repair improved with time?: a population-based analysis. Ann Surg 2003;237:129-35.

8. Plymale MA, Ragulojan R, Davenport DL, Roth JS. Ventral and incisional hernia: the cost of comorbidities and complications. Surg Endosc 2017;31:341-51.

9. Tastaldi L, Petro CC, Krpata DM, Alkhatib H, Fafaj A, et al. History of surgical site infection increases the odds for a new infection after open incisional hernia repair. Surgery 2019;166:88-93.

10. Holihan JL, Alawadi Z, Martindale RG, Roth JS, Wray CJ, et al. Adverse events after ventral hernia repair: the vicious cycle of complications. J Am Coll Surg 2015;221:478-85.

11. Leppin AL, Gionfriddo MR, Kessler M, Brito JP, Mair FS, et al. Preventing 30-day hospital readmissions: a systematic review and metaanalysis of randomized trials. JAMA Intern Med 2014;174:1095-107.

12. Desborough JP. The stress response to trauma and surgery. Br J Anaesth 2000;85:109-17.

13. Serhan CN. Discovery of specialized pro-resolving mediators marks the dawn of resolution physiology and pharmacology. Mol Aspects Med 2017;58:1-11.

14. Serhan CN. Treating inflammation and infection in the 21st century: new hints from decoding resolution mediators and mechanisms. FASEB J 2017;31:1273-88

15. Berger RL, Li LT, Hicks SC, Davila JA, Kao LS, et al. Development and validation of a risk-stratification score for surgical site occurrence and surgical site infection after open ventral hernia repair. J Am Coll Surg 2013;217:974-82.

16. Sugerman HJ, Kellum Jr JM, Reines HD, DeMaria EJ, Newsome HH, et al. Greater risk of incisional hernia with morbidly obese than steroid-dependent patients and low recurrence with prefascial polypropylene mesh. Am J Surg 1996;171:80-4.

17. Puzziferri N, Austrheim-Smith IT, Wolfe BM, Wilson SE, Nguyen NT. Three-year follow-up of a prospective randomized trial comparing laparoscopic versus open gastric bypass. Ann Surg 2006;243:181-8.

18. Desai KA, Razavi SA, Hart AM, Thompson PW, Losken A. The effect of BMI on outcomes following complex abdominal wall reconstructions. Ann Plast Surg 2016;76:S295-7.

19. Lin HJ, Spoerke N, Deveney C, Martindale R. Reconstruction of complex abdominal wall hernias using acellular human dermal matrix: a single institution experience. Am J Surg 2009;197:599-603.

20. Sauerland S, Korenkov M, Kleinen T, Arndt M, Paul A. Obesity is a risk factor for recurrence after incisional hernia repair. Hernia 2004;8:42-6.

21. Spaniolas K, Kasten KR, Mozer AB, Sippey ME, Chapman WHH, et al. Synchronous ventral hernia repair in patients undergoing bariatric surgery. Obes Surg 2015;25:1864-8.

22. Sorensen LT, Hemmingsen U, Kallehave F, Wille-Jørgensen P, Kjaergaard J, et al. Risk factors for tissue and wound complications in gastrointestinal surgery. Ann Surg 2005;241:654-8.

23. Finan KR, Vick CC, Kiefe CI, Neumayer L, Hawn MT. Predictors of wound infection in ventral hernia repair. Am J Surg 2005;190:676-81.

24. Sørensen LT, Hemmingsen UB, Kirkeby LT, Kallehave F, Jørgensen LN. Smoking is a risk factor for incisional hernia. Arch Surg 2005;140:119-23.

25. Sorensen LT, Karlsmark T, Gottrup F. Abstinence from smoking reduces incisional wound infection: a randomized controlled trial. Ann Surg 2003;238:1-5.

26. DeLancey JO, Blay Jr E, Hewitt DB, Engelhardt K, Bilimoria KY, et al. The effect of smoking on 30-day outcomes in elective hernia repair. Am J Surg 2018;216:471-4. 
27. Sørensen LT, Hørby J, Friis E, Pilsgaard B, Jørgensen T. Smoking as a risk factor for wound healing and infection in breast cancer surgery. Eur J Surg Oncol 2002;28:815-20.

28. Yang GP, Longaker MT. Abstinence from smoking reduces incisional wound infection: a randomized, controlled trial. Ann Surg 2003;238:6-8.

29. Jensen JA, Goodson WH, Hopf HW, Hunt TK. Cigarette smoking decreases tissue oxygen. Arch Surg 1991;126:1131-4.

30. Knuutinen A, Kokkonen N, Risteli J, Vähäkangas K, Kallioinen M, et al. Smoking affects collagen synthesis and extracellular matric turnover in human skin. Br J Dermatol 2002;146:588-94.

31. Sørensen LT, Toft BG, Rygaard J, Ladelund S, Paddon M, et al. Effect of smoking, smoking cessation, and nicotine patch on wound dimension, vitamin C, and systemic markers of collagen metabolism. Surgery 2010;148:982-90.

32. Mills E, Eyawo O, Lockhart I, Kelly S, Wu P, et al. Smoking cessation reduces postoperative complications: a systematic review and meta-analysis. Am J Med 2011;124:144-54.e8.

33. Lindstrom D, Azodi OS, Wladis A, Tønnesen H, Linder S, et al. Effects of a perioperative smoking cessation intervention on postoperative complications: a randomized trial. Ann Surg 2008;248:739-45.

34. Benowitz NL, Hukkanen J, Jacob P 3rd. Nicotine chemistry, metabolism, kinetics and biomarkers. Handb Exp Pharmacol 2009;29-60.

35. Dronge AS, Perkal MF, Kancir S, Concato J, Aslan M, et al. Long-term glycemic control and postoperative infectious complications. Arch Surg 2006;141:375-80.

36. Kwon S, Thompson R, Dellinger P, Yanez D, Farrohki E, et al. Importance of perioperative glycemic control in general surgery: a report from the Surgical Care and Outcomes Assessment Program. Ann Surg 2013;257:8-14.

37. Won EJ, Lehman EB, Geletzke AK, Tangel MR, Matsushima K, et al. Association of postoperative hyperglycemia with outcomes among patients with complex ventral hernia repair. JAMA Surg 2015;150:433-40.

38. Turina M, Fry DE, Polk Jr HC. Acute hyperglycemia and the innate immune system: clinical, cellular, and molecular aspects. Crit Care Med 2005;33:1624-33.

39. Van den Berghe G, Wouters P, Weekers F, Verwaest C, Bruyninckx F, et al. Intensive insulin therapy in critically ill patients. N Engl J Med 2001;345:1359-67.

40. Finfer S, Liu B, Chittock DR, Norton R, Myburgh JA, et al. Hypoglycemia and risk of death in critically ill patients. N Engl J Med 2012;367:1108-18.

41. Ramos M, Khalpey Z, Lipsitz S, Steinberg J, Panizales MT, et al. Relationship of perioperative hyperglycemia and postoperative infections in patients who undergo general and vascular surgery. Ann Surg 2008;248:585-91.

42. Ata A, Lee J, Bestle SL, Desemone J, Stain SC. Postoperative hyperglycemia and surgical site infection in general surgery patients. Arch Surg 2010;145:858-64.

43. Endara M, Masden D, Goldstein J, Gondek S, Steinber J, et al. The role of chronic and perioperative glucose management in high-risk surgical closures: a case for tighter glycemic control. Plast Reconstr Surg 2013;132:996-1004.

44. DeSantis AJ, Schmeltz LR, Schmidt K, O'Shea-Mahler E, Rhee C, et al. Inpatient management of hyperglycemia: the northwestern experience. Endocr Pract 2005;12:491-505.

45. Cruz-Jentoft AJ, Baeyens JP, Bauer JM, Boirie Y, Cederholm T, et al. Sarcopenia: European consensus on definition and diagnosis: report of the European working group on sarcopenia in older people. Age Ageing 2010;39:412-23.

46. Prado CMM, Lieffers JR, McCargar LJ, Reiman T, Sawyer MB, et al. Prevalence and clinical implications of sarcopenic obesity in patients with solid tumours of the respiratory and gastrointestinal tracts: a population-based study. Lancet Oncol 2008;9:629-35.

47. Narici MV, Maffulli N. Sarcopenia: characteristics, mechanisms and functional significance. Br Med Bull 2010;95:139-59.

48. Lieffers JR, Bathe OF, Fassbender K, Winget M, Baracos VE. Sarcopenia is associated with postoperative infection and delayed recovery from colorectal cancer resection surgery. Br J Cancer 2012;107:931-6.

49. Moisey LL, Mourtzakis M, Cotton BA, Premji T, Heyland DK, et al. Skeletal muscle predicts ventilator-free days, ICU-free days, and mortality in elderly in ICU patients. Crit Care 2013;17:R206.

50. Montano-Loza AJ, Meza-Junco J, Prado CMM, Lieffers JR, Baracos VE, et al. Muscle wasting is associated with mortality in patients with cirrhosis. Clin Gastroenterol Hepatol 2012;10:166-73, 173.e1.

51. Okumura S, Kaido T, Hamaguchi Y, Fujimoto Y, Kobayashi A, et al. Impact of the preoperative quantity and quality of skeletal muscle on outcomes after resection of extrahepatic biliary malignancies. Surgery 2016;159:821-33.

52. Pisitsak C, Lee JGH, Boyd JH, Coxson HO, Russell JA, et al. Increased ratio of visceral to subcutaneous adipose tissue in septic patients is associated with adverse outcome. Crit Care Med 2016;44:1966-73.

53. Weig T, Milger K, Langhans B, Janitza S, Sisic A, et al. Core muscle size predicts postoperative outcome in lung transplant candidates. Ann Thorac Surg 2016;101:1318-25.

54. Barnes LA, Li AY, Wan DC, Momeni A. Determining the impact of sarcopenia on postoperative complications after ventral hernia repair. J Plast Reconstr Aesthet Surg 2018;71:1260-8.

55. Siegal SR, Guimaraes AR, Lasarev MR, Martindale RG, Orenstein SB. Sarcopenia and outcomes in ventral hernia repair: a preliminary review. Hernia 2018;22:645-52.

56. Deutz NEP, Ashurst I, Ballesteros MD, Bear DE, Cruz-Jentoft AJ, et al. The underappreciated role of low muscle mass in the management of malnutrition. J Am Med Dir Assoc 2019;20:22-7.

57. Bilimoria KY, Liu Y, Paruch JL, Zhou L, Kmiecik TE, et al. Development and evaluation of the universal ACS NSQIP surgical risk calculator: a decision aid and informed consent tool for patients and surgeons. J Am Coll Surg 2013;217:833-42.e1-3.

58. Reddy S, Contreras CM, Singletary B, Bradford TM, Waldrop MG, et al. Timed stair climbing is the single strongest predictor of perioperative complications in patients undergoing abdominal surgery. J Am Coll Surg 2016;222:559-66.

59. Minnella EM, Awasthi R, Gillis C, Fiore Jr JF, Liberman AS, et al. Patients with poor baseline walking capacity are most likely to improve their functional status with multimodal prehabilitation. Surgery 2016;160:1070-9. 
60. Li C, Carli F, Lee L, Charlebois P, Stein B, et al. Impact of a trimodal prehabilitation program on functional recovery after colorectal cancer surgery: a pilot study. Surg Endosc 2013;27:1072-82.

61. Barakat HM, Shahin Y, Khan JA, McCollum PT, Chetter IC. Preoperative supervised exercise improves outcomes after elective abdominal aortic aneurysm repair: a randomized controlled trial. Ann Surg 2016;264:47-53.

62. Hijazi Y, Gondal U, Aziz O. A systematic review of prehabilitation programs in abdominal cancer surgery. Int J Surg 2017;39:156-62.

63. Liang MK, Bernardi K, Holihan JL, Cherla DV, Escamilla R, et al. Modifying risks in ventral hernia patients with prehabilitation: a randomized controlled trial. Ann Surg 2018;268:674-80.

64. Trépanier M, Minnella EM, Paradis T, Awasthi R, Kaneva P, et al. Improved disease-free survival after prehabilitation for colorectal cancer surgery. Ann Surg 2019;270:493-501.

65. Martindale RG, McClave SA, Vanek VW, McCarthy M, Robert P, et al. Guidelines for the provision and assessment of nutrition support therapy in the adult critically ill patient: society of critical care medicine and american society for parenteral and enteral nutrition: executive summary. Crit Care Med 2009;37:1757-61.

66. Jie B, Jiang ZM, Nolan MT, Zhu SN, Yu K, et al. Impact of preoperative nutritional support on clinical outcome in abdominal surgical patients at nutritional risk. Nutrition 2012;28:1022-7.

67. Johansen N, Kondrup J, Plum LM, Bak L, Nørregaard P, et al. Effect of nutritional support on clinical outcome in patients at nutritional risk. Clin Nutr 2004;23:539-50.

68. Starke J, Schneider H, Alteheld B, Stehle P, Meier R. Short-term individual nutritional care as part of routine clinical setting improves outcome and quality of life in malnourished medical patients. Clin Nutr 2011;30:194-201.

69. Heyland DK, Dhaliwal R, Jiang X, Day AG. Identifying critically ill patients who benefit the most from nutrition therapy: the development and initial validation of a novel risk assessment tool. Crit Care 2011;15:R268.

70. Rahman A, Hasan RM, Agarwala R, Martin C, Day AG, et al. Identifying critically-ill patients who will benefit most from nutritional therapy: further validation of the "modified NUTRIC" nutritional risk assessment tool. Clin Nutr 2016;35:158-62.

71. Daley J, Khuri SF, Henderson W, Hur K, Gibbs JO, et al. Risk adjustment of the postoperative mortality rate for the comparative assessment of the quality of surgical care: results of the national veterans affairs surgical risk study. J Am Coll Surg 1997;185:328-40.

72. Bauer J, Biolo G, Cederholm T, Cesari M, Cruz-Jentoft AJ, et al. Evidence-based recommendations for optimal dietary protein intake in older people: a position paper from the PROT-AGE Study Group. J Am Med Dir Assoc 2013;14:542-59.

73. Churchward-Venne TA, Tieland M, Verdijk LB, Leenders M, Dirks ML, et al. There are no nonresponders to resistance-type exercise training in older men and women. J Am Med Dir Assoc 2015;16:400-11.

74. Deutz NEP, Bauer JM, Barazzoni R, Biolo G, Boirie Y, et al. Protein intake and exercise for optimal muscle function with aging: recommendations from the ESPEN Expert Group. Clin Nutr 2014;33:929-36.

75. Fiatarone MA, O'Neill EF, Ryan ND, Clements KM, Solares GR, et al. Exercise training and nutritional supplementation for physical frailty in very elderly people. NEJM 1994;330:1769-75.

76. Houston DK, Nicklas BJ, Ding J, Harris TB, Tylavsky FA, et al. Dietary protein intake is associated with lean mass change in older, community-dwelling adults: the health, aging, and body composition (health ABC) study. Am J Clin Nutr 2008;87:150-5.

77. Witard OC, McGlory C, Hamilton DL, Phillips SM. Growing older with health and vitality: a nexus of physical activity, exercise and nutrition. Biogerontology 2016;17:529-46.

78. Braga M, Gianotti L, Nespoli L, Radaelli G, Di Carlo V. Nutritional approach in malnourished surgical patients: a prospective randomized study. Arch Surg 2002;137:174-80.

79. Braga M, Gianotti L, Vignali A, Di Carlo V. Preoperative oral arginine and n-3 fatty acid supplementation improves the immunometabolic host response and outcome after colorectal resection for cancer. Surgery 2002;132:805-14.

80. Braga M, Gianotti L, Vignali A, Schmid A, Nespoli L, et al. Hospital resources consumed for surgical morbidity: effects of preoperative arginine and omega-3 fatty acid supplementation on costs. Nutrition 2005;21:1078-86.

81. Gianotti L, Braga M, Nespoli L, Radaelli G, Beneduce A, et al. A randomized controlled trial of preoperative oral supplementation with a specialized diet in patients with gastrointestinal cancer. Gastroenterology 2002;122:1763-70.

82. Dalli J, Serhan C. Macrophage proresolving mediators-the when and where. Microbiol Spectr 2016;4.

83. Zhu X, Pribis JP, Rodriguez PC, Morris Jr SM, Vodovotz Y, et al. The central role of arginine catabolism in T-cell dysfunction and increased susceptibility to infection after physical injury. Ann Surg 2014;259:171-8.

84. MacLeod AS, Mansbridge JN. The innate immune system in acute and chronic wounds. Adv Wound Care (New Rochelle) 2016;5:65-78.

85. Serhan CN. Pro-resolving lipid mediators are leads for resolution physiology. Nature 2014;510:92-101.

86. Serhan CN, Levy BD. Resolvins in inflammation: emergence of the pro-resolving superfamily of mediators. J Clin Invest 2018;128:2657-69.

87. Drover JW, Dhaliwal R, Weitzel L, Wischmeyer PE, Ochoa JB, et al. Perioperative use of arginine-supplemented diets: a systematic review of the evidence. J Am Coll Surg 2011;212:385-99.

88. Marimuthu K, Varadhan KK, Ljungqvist O, Lobo DN. A meta-analysis of the effect of combinations of immune modulating nutrients on outcome in patients undergoing major open gastrointestinal surgery. Ann Surg 2012;255:1060-8.

89. Adiamah A, Skořepa P, Weimann A, Lobo DN. The impact of preoperative immune modulating nutrition on outcomes in patients undergoing surgery for gastrointestinal cancer: a systematic review and meta-analysis. Ann Surg 2019;270:247-56.

90. Osland E, Hossain MB, Khan S, Memon MA. Effect of timing of pharmaconutrition (immunonutrition) administration on outcomes of elective surgery for gastrointestinal malignancies: a systematic review and meta-analysis. JPEN J Parenter Enteral Nutr 2014;38:53-69.

91. Mazaki T, Ishii Y, Murai I. Immunoenhancing enteral and parenteral nutrition for gastrointestinal surgery: a multiple-treatments metaanalysis. Ann Surg 2015;261:662-9.

92. Awad S, Lobo DN. Metabolic conditioning to attenuate the adverse effects of perioperative fasting and improve patient outcomes. Curr Opin Clin Nutr Metab Care 2012;15:194-200.

93. Gianotti L, Biffi R, Sandini M, Marrelli D, Vignali A, et al. Preoperative oral carbohydrate load versus placebo in major elective abdominal 
surgery (PROCY): a randomized, placebo-controlled, multicenter, Phase III trial. Ann Surg 2018;267:623-30.

94. Awad S, Varadhan KK, Ljungqvist O, Lobo DN. A meta-analysis of randomised controlled trials on preoperative oral carbohydrate treatment in elective surgery. Clin Nutr 2013;32:34-44.

95. Fearon KCH, Ljungqvist O, Von Meyenfeldt M, Revhaug A, Dejong CHC, et al. Enhanced recovery after surgery: a consensus review of clinical care for patients undergoing colonic resection. Clin Nutr 2005;24:466-77.

96. Soop M, Nygren J, Myrenfors P, Thorell A, Ljungqvist O. Preoperative oral carbohydrate treatment attenuates immediate postoperative insulin resistance. Am J Physiol Endocrinol Metab 2001;280:576-83.

97. Smith MD, McCall J, Plank L, Herbison GP, Soop M, et al., Preoperative carbohydrate treatment for enhancing recovery after elective surgery. Cochrane Database Syst Rev 2014;CD009161.

98. Amer MA, Smith MD, Herbison GP, Plank LD, McCall JL. Network meta-analysis of the effect of preoperative carbohydrate loading on recovery after elective surgery. Br J Surg 2017;104:187-97.

99. Weimann A, Braga M, Carli F, Higashiguchi T, Hübner M, et al. ESPEN guideline: Clinical nutrition in surgery. Clin Nutr 2017;36:623-50.

100. Webster J, Osborne S. Preoperative bathing or showering with skin antiseptics to prevent surgical site infection. Cochrane Database Syst Rev 2015;CD004985.

101. Prabhu AS, Krpata DM, Phillips S, Huang L, Haskins IN, et al. Preoperative chlorhexidine gluconate use can increase risk for surgical site infections after ventral hernia repair. J Am Coll Surg 2017;224:334-40.

102. Wong VW, Martindale RG, Longaker MT, Gurtner GC. From germ theory to germ therapy: skin microbiota, chronic wounds, and probiotics. Plast Reconstr Surg 2013;132:854e-61e.

103. Swenson BR., Hedrick TL, Metzger R, Bonatti H, Pruett TL, et al. Effects of preoperative skin preparation on postoperative wound infection rates: a prospective study of 3 skin preparation protocols. Infect Control Hosp Epidemiol 2009;30:964-71.

104. Darouiche RO, Wall Jr MJ, Itani KMF, Otterson MF, Webb AL, et al. Chlorhexidine-alcohol versus povidone-iodine for surgical-site antisepsis. N Engl J Med 2010;362:18-26.

105. SwensonBR, Sawyer RG. Importance of alcohol in skin preparation protocols. Infect Control Hosp Epidemio 2010;31:977.

106. Bode LGM, Kluytmans JAJW, Wertheim HFL, Bogaers D, Vandenbroucke-Grauls CMJE, et al. Preventing surgial-site infections in nasal carriers of staphylococcus aureus. N Engl J Med 2010;362:9-17.

107. KimDH, Spencer M, Davidson SM, Li L, Shaw JD, et al. Institutional prescreening for detection and eradication of methicillin-resistant Staphylococcus aureus in patients undergoing elective orthopaedic surgery. J Bone Joint Surg Am 2010;92:1820-6.

108. BratzlerDW, Dellinger EP, Olsen KM, Perl TM, Auwaerter PG, et al. Clinical practice guidelines for antimicrobial prophylaxis in surgery. Am J Health Syst Pharm 2013;70:195-283.

109. Koch CG, Li L, Hixson E, Tang A, Gordon S, et al. Is it time to refine? An exploration and simulation of optimal antibiotic timing in general surgery. J Am Coll Surg 2013;217:628-35.

110. Freeman JT, Anderson DJ, Hartwig MG, Sexton DJ. Surgical site infections following bariatric surgery in community hospitals: a weighty concern? Obes Surg 2011;21:836-40.

111. Hanley MJ, Abernethy DR, Greenblatt DJ. Effect of obesity on the pharmoacokinetics of drugs in humans. Clin Pharmacokinet 2010;49:71-87.

112. Wong A, Lee S, Nathan NS, Wang F, Hansen S, et al. Postoperative prophylactic antibiotic use following ventral hernia repair with placement of surgical drains reduces the postoperative surgical-site infection rate. Plast Reconstr Surg 2016;137:285-94.

113. Osmon DR. Antimicrobial prophylaxis in adults. Mayo Clin Proc 2011;75:98-109.

114. Berbari EF, Osmon DR, Lahr B, Eckel-Passow JE, Tsaras G, et al. The Mayo prosthetic joint infection risk score: implication for surgical site infection reporting and risk stratification. Infect Control Hosp Epidemiol 2012;33:774-81.

115. Bratzler DW, Houck PM; Workgroup SIPGW. Antimicrobial prophylaxis for surgery: an advisory statement from the national surgical infection prevention project. Am J Surg 2004;189:395-404.

116. Suehiro T, Hirashita T, Araki S, Matsumata T, Tsutsumi S, et al. Prolonged antibiotic prophylaxis longer than 24 hours does not decrease surgical site infection after elective gastric and colorectal surgery. Hepato-Gastroenterology 2008;55:1636-9.

117. Hayakawa M, Asahara T, Henzan N, Murakami H, Yamamoto H, et al. Dramatic changes of the gut flora immediately after severe and sudden insults. Dig Dis Sci 2011;56:2361-5.

118. Klingensmith NJ, Coopersmith CM. The gut as the motor of multiple organ dysfunction in critical illness. Crit Care Clin 2016;32:203-12.

119. Krezalek MA, DeFazio J, Zaborina O, Zaborin A, Alverdy JC, et al. The shift of an intestinal "microbiome" to a "pathobiome" governs the course and outcome of sepsis following surgical injury. Shock 2016;45:475-82.

120. McClaveSA, Lowen CC, Martindale RG. The 2016 ESPEN arvid wretlind lecture: the gut in stress. Clin Nutr 2018;37:19-36.

121. Turne JR. Intestinal mucosal barrier function in health and disease. Nat Rev Immunol 2009;9:799-809.

122. FAO/WHO Expert Consultation. Health and nutritional properties of probiotics in food including powder milk with live lactic acid bacteria. 2001.

123. Kotzampassi K, Stavrou G, Damoraki G, Georgitsi M, Basdanis G, et al. A four-probiotics regimen reduces postoperative complications after colorectal surgery: a randomized, double-blind, placebo-controlled study. World J Surg 2015;39:2776-83.

124. Sikorska H, Smoragiewicz W. Role of probiotics in the prevention and treatment of meticillin-resistant Staphylococcus aureus infections. Int J Antimicrob Agents 2013;42:475-81.

125. Wu XD, Xu W, Liu MM, Hu KJ, Sun YY, et al. Efficacy of prophylactic probiotics in combination with antibiotics versus antibiotics alone for colorectal surgery: a meta-analysis of randomized controlled trials. J Surg Oncol 2018;117:1394-404.

126. Arumugam S, Lau CSM, Chamberlain RS. Probiotics and synbiotics decrease postoperative sepsis in elective gastrointestinal surgical patients: a meta-analysis. J Gastrointest Surg 2016;20:1123-31.

127. Lytvyn L, Quach K, Banfield L, Johnston BC, Mertz D, et al. Probiotics and synbiotics for the prevention of postoperative infections following abdominal surgery: a systematic review and meta-analysis of randomized controlled trials. J Hosp Infect 2016;92:130-9. 
128. Chowdhury AH, Adiamah A, Kushairi A, Varadhan KK, Krznaric Z, et al. Perioperative probiotics or synbiotics in adults undergoing elective abdominal surgery: a systematic review and meta-analysis of randomized controlled trials. Ann Surg 2019.

129. Ljungqvist O, Scott M, Fearon KC. Enhanced recovery after surgery: a review. JAMA Surg 2017;152:292-8.

130. Burgess LC, Wainwright TW. What is the evidence for early mobilisation in elective spine surgery? a narrative review. Healthcare (Basel) 2019;7.

131. Stein MJ, Frank SG, Lui A, Zhang T, Zhang J, et al. Ambulatory latissimus dorsi flap breast reconstruction: a prospective cohort study of an enhanced recovery after surgery (ERAS) protocol. J Plast Reconstr Aesthet Surg 2019;72:1950-55.

132. Reid K, Pockney P, Draganic B, Smith SR. Barrier wound protection decreases surgical site infection in open elective colorectal surgery: a randomized clinical trial. Dis Colon Rectum 2010;53:1374-80.

133. Horiuchi T,Tanishima H, Tamagawa K, Matsuura I, Nakai H, et al. Randomized, controlled investigation of the anti-infective properties of the Alexis retractor/protector of incision sites. J Trauma 2007;62:212-5.

134. Gaines S, Luo JN, Gilbert J, Zaborina O, Alverdy JC, et al. Optimum operating room environment for the prevention of surgical site infections. Surg Infect (Larchmt) 2017;18:503-7.

135. Webster J. Alghamdi A. Use of plastic adhesive drapes during surgery for preventing surgical site infection. Cochrane Database Syst Rev 2015;CD006353.

136. Krpata DM, Prabhu AS, Carbonell AM, Haskins IN, Phillips S,et al. Drain placement does not increase infectious complications after retromuscular ventral hernia repair with synthetic mesh: an AHSQC analysis. J Gastrointest Surg 2017;21:2083-89.

137. Greif R, Akça O, Horn EP, Kurz A, Sessler DI, et al. Supplemental perioperaive oxygen to reduce the incidence of surgical-wound infections. N Engl J Med 2000;342:161-7.

138. Belda FJ, Aguilera L, Asunción JG, Alberti J, Vicente R, et al. Supplemental perioperative oxygen and the risk of surgical wound infection: a randomized controlled trial. JAMA 2005;294:2035-42.

139. Al-Niaim A, Safdar N. Supplemental perioperative oxygen for reducing surgical site infection: a meta-analysis. J Eval Clin Pract 2009;15:360-5.

140. Tan M, Law LS, Gan TJ. Optimizing pain management to facilitate enhanced recovery after surgery pathways. Can J Anaesth 2015;62:203-18.

141. Sobol-Kwapinska M, Bąbel P, Plotek W,Stelcer B. Psychological correlates of acute postsurgical pain: a systematic review and metaanalysis. Eur J Pain 2016;20:1573-86.

142. Stamenkovic DM, Rancic NK, Latas MB, Neskovic V, Rondovic GR, et al. Preoperative anxiety and implications on postoperative recovery: what can we do to change our history. Minerva Anestesiol 2018;84:1307-17.

143. Nilsson U, Rawal N, Enqvist B, Unosson M. Analgesia following music and therapeutic suggestions in the PACU in ambulatory surgery; a randomized controlled trial. Acta Anaesthesiol Scand 2003;47:278-83.

144. Bradt J, Dileo C. Music interventions for mechanically ventilated patients. Cochrane Database Syst Rev 2014;12:CD006902. 